\title{
IRMÃS JAMAIS: FICÇÃO DE SI ENTRE TERNURA E AMARGURA ${ }^{1}$ \\ SORELLE MAI: SELF-FICTION AMONG TENDERNESS AND BITTERNESS
}

Julia S. SCAMPARINI ${ }^{2}$

\begin{abstract}
Resumo: Para realizar Irmãs Jamais (2010), Marco Bellocchio optou por unir uma necessidade prática a uma operação afetiva: ao mesmo tempo em que usou seus familiares e cenário natal como matériaprima imagética para ensinar seus alunos do Laboratorio Fare Cinema, fez um registro de sua família em filme. Ao realizar esta ficção de si, deslocou a discussão banal entre ficção e realidade e rumou a reflexões potentes sobre o cinema e a vida por meio de uma escrita pessoal indireta.
\end{abstract}

Palavras-chave: Autoficção. Imagem documental. Memória. Marco Bellocchio.

Abstract: In order to make Sorelle Mai (2010), Marco Bellocchio decided to put together both a practical necessity and an affective operation: he used his family and birthplace as raw material for his lessons at Laboratorio Fare Cinema and at the same time he created a record of his family in film. By doing so, he offered something more than the usual real-fiction discussion: the film proposes a strong reflection on cinema and life through an indirect personal writing.

Keywords: Autofiction. Documental image. Memory. Marco Bellocchio.

\section{Telas autobiográficas}

O cinema que, de alguma forma, se refere explicitamente ou remete ao próprio diretor é mais frequentemente discutido no âmbito do documentário, sobretudo quando se trata de produção recente, pertencente a um recorte temporal que pode ser definido, grosso modo, das décadas finais do século XX às décadas iniciais do século XXI. Circunscritos neste espaço de tempo, tais filmes vêm sendo categorizados como ensaios e filmes-diário - metáforas terminológicas que expõem a aproximação dos mesmos a formas de uso íntimo ou literáriolivre da linguagem verbal -, e também como documentários performativos e autobiográficos, os quais usualmente estabelecem vínculo com aspectos da ficção e da literatura. Por mais que façam parte do grande guarda-chuva do gênero documentário, as escritas de si no cinema flertam com outros modos discursivos, ou são por eles formadas e, portanto, configuram-se como uma forma de transgressão ao que se entende por documentário, ficção e, claro, por

\footnotetext{
${ }^{1}$ Parte deste artigo foi publicada como resumo expandido nos anais digitais do XXI Encontro SOCINE, disponíveis em: https://associado.socine.org.br/anais/2017/

${ }^{2}$ Professora Adjunta do Instituto de Letras da UERJ - Setor de Italiano. Doutora em Letras Neolatinas - Italiano (UERJ). juliascamparini@gmail.com
} 
autoria - desde sempre uma questão para o cinema. O cineasta que decide servir-se da própria figura ou contar a si mesmo abraça de antemão estes deslimites, põe os pés nas linhas imaginárias que definem as fronteiras entre artes e gêneros, em um exercício de autoconfronto, muitas vezes, inconsciente (como pode ser o caso dos filmes de família) e, outras vezes, bastante desejado, como em filmes resultantes de pesquisa histórica e de arquivo, ou em cinemas mais experimentais.

Inserir o filme Irmãs Jamais (Sorelle Mai, no original), de 2010, nas discussões que contemplam os gêneros acima mencionados tem como motivação e objetivo elucubrar sobre o projeto artístico no qual Marco Bellocchio se engajou ao realizar um drama ficcional com imagens de sua família e de sua cidade natal, imagens produzidas por alunos de sua escola de cinema, o Laboratorio Fare Cinema, em seis verões, entre 1999 e 2008. Em um momento artístico em que a produção subjetiva ganha proporções até mesmo exageradas, segundo a crítica (pois muitos filmes parecem motivados por vaidade mais do que por reflexões estéticas, políticas ou sociais), isto é, dada a moldura discursiva que a época nos impõe, esse filme surge como uma provocação, uma ficção de si que finca pés em imagens de família fortemente documentais, mas abre mão da imagem, da voz ou de qualquer traço da materialidade do diretor.

\section{Ficções de si}

$\mathrm{Na}$ literatura, a discussão sobre a subjetividade do autor na obra tem se concentrado (não exclusiva, mas principalmente) no âmbito da autoficção, um quase gênero narrativo cuja definição passa pela indiscernibilidade dos regimes ficcional e documental, que, na literatura, são tradicionalmente representados pelo romance e pela (auto)biografia. As tentativas de definição para o termo percorrem narrativas baseadas em acontecimentos reais contadas de forma romanceada, bem como narrativas ancoradas em linguagem e formato mais documentais que contam histórias fictícias. Entre um polo e outro, há uma proliferação de escritas de si que impede uma definição que as una definitivamente, mas que, ao mesmo tempo, demonstra a riqueza de um fenômeno contemporâneo que atravessa outras artes, sobretudo o cinema. Ademais, e mais importante, demonstra que esse fenômeno traduz uma preocupação artística sobre o exercício da subjetividade nos dias de hoje, uma curiosidade ou desassossego que observa desde o discurso banalizado das redes sociais, até trabalhos políticos, sociais ou estéticos que partem do que é pessoal para aportar no universal. 
Ao lado da indiscernibilidade dos regimes, nas autoficções, é de costume que o aut-or seja identificado com o protagonista através do nome e sobrenome duplicados, das iniciais dos mesmos, ou da fotografia, nas prosas literárias. No cinema, o que ocorre é a aparição do diretor, que se torna personagem de si mesmo, ou a presença de sua voz, seja como entrevistador, pesquisador, comentador, narrador. De alguma forma, pensados em união e consideradas as diferenças óbvias de cada um desses discursos, nas escritas de si do cinema e da literatura, há comumente a materialização da autoria no suporte (SCAMPARINI, 2013; 2015). Mas a inscrição de si, nos melhores casos, desdobra-se e, ao mesmo tempo, problematiza o próprio suporte, o próprio dispositivo, ou seja, problematiza não somente a autoria (e/ou o nome próprio), mas também o que se entende por romance, documentário, realidade, ficção.

A transgressão, no que concerne aos limites do gênero ou regime ${ }^{3}$ com que a obra inicialmente se identifica, dá-se principalmente com respeito ao modo de leitura, caracterizado por um círculo vicioso em que se alternam a adesão a um pacto ficcional e a um pacto autobiográfico (LEJEUNE, 2008). A impermanência de um único pacto de leitura é impulso para uma discussão que se perpetua até hoje sobre o que é a autoficção em relação, principalmente, à autobiografia (que pressupõe um pacto autobiográfico) e ao romance memorialista (que mantém o pacto ficcional), mas também parece ter instaurado um dever de decisão para o leitor. Em discussões informais, percebe-se que a opção majoritária é a de ler as informações contidas em um romance autoficcional como reais e, mesmo sendo possível tratálas como ficcionais, esta é a opção de poucos. Não obstante, muitas vezes, é justamente esta a proposta do autor em sua defesa da obra como romance em detrimento de ser um documento. No cinema, a ambiguidade ou circularidade dos regimes também se tornou numerosa, considerados o cinema mais autoral e também o amador ${ }^{4}$, indicando a oferta de um ritmo de recepção/percepção bastante contemporâneo. Pois, sabemos que, mesmo sendo o documentário um gênero híbrido, mantém-se a expectativa de um regime documental. Ou seja, inicialmente incomodado ao tentar entender o regime com que se identifica o filme ou o livro, o leitor/expectador contemporâneo tem tido que se acostumar a um efeito de real do romance e a um apelo à ficção do documentário. Martoni e Ulm (2016) chamam atenção ao ritmo que novos meios impõem aos corpos, recuperando o pensamento de Vilém Flusser de que o agir e o querer

\footnotetext{
${ }^{3}$ Ao nos referirmos ao oposto tácito real x ficção, optamos pelo termo regime, ao passo que o termo gênero se refere aos formatos artísticos já consagrados, como romance, biografia, documentário, drama, dentre outros tipos e subtipos.

${ }^{4}$ Em festivais de cinema documentário, como o $E$ tudo verdade, observa-se que o número de trabalhos que escolhem mesclar ficção e documentário é bastante elevado e não se restringe às escritas de si.
} 
humano são tecnoculturalmente codificados, para propor o que chamam de "ritual da percepção". Dizem eles:

Com essa expressão, queremos apontar que: 1) nossa percepção está condicionada, na
verdade, por um conjunto de regras práticas que temos de repetir cotidianamente para
que as coisas apareçam; e 2) não há percepção "privada", significando que ela é
sempre um fato coletivo de crença (2016, p. 176).

Sem, neste momento, aprofundarmo-nos no conceito, ele nos indica que, por conta da circularidade dos pactos, as escritas de si têm, em seu conjunto, configurado um novo ritmo de leitura que se aloca entre os regimes de realidade e de ficção, oferecendo uma nova forma de leitura/visão que, se ainda causa estranhamento, pode vir a instaurar um novo ritual de percepção por parte do espectador.

No cinema, as discussões sobre a subjetividade em filme são bem classificadas por Gonçalo (2012), a partir da guinada subjetiva identificada por Beatriz Sarlo em Tempo Passado. Dentre as categorias descritas, estão os filmes cujo dispositivo é o olhar do diretor que se volta ao passado e resgata memórias, discursos, documentos e imagens de sua família. Gonçalo restringe-se, neste seu trabalho, ao cinema documentário brasileiro, e cita filmes hoje já considerados clássicos deste formato, como Passaporte Húngaro (Sandra Kogut, 2001), 33 (Kiko Goifman, 2003) e Santiago (João Moreira Salles, 2007), mas aponta para uma prática global. O canadense Histórias que contamos (Sarah Polley, 2012), por exemplo, parte de uma investigação a que se propõe a diretora a respeito da mãe, falecida durante sua infância. Entre a colheita de depoimentos e a apresentação do equipamento de filmagem, o que instaura o modo documentário, a cineasta inclui cenas aparentemente de arquivo, por conta da estética análoga à produzida pela câmera Super $8 \mathrm{~mm}$, mas que são encenações de situações banais e familiares, conduzidas por uma atriz semelhante à mãe, para recuperar um passado que não foi encontrado em película.

Também em Uma longa viagem (2013), de Lucia Murat, as imagens do passado que assistimos são tidas como documentais, pertencentes ao arquivo pessoal do irmão da diretora, que é o protagonista do filme. Somente em um momento posterior (ou anterior, ou mesmo que nunca ocorrerá), ao ler sobre o filme, é que se vem a saber que muitas das imagens vistas se tratavam de imagens emprestadas, que comparecem no documentário para compor uma narrativa, para remendar um esquecimento ou a lacuna imagética de uma memória desejada em matéria. 
Se uma das características muito fortes desta época é o exercício da subjetividade e da memória na arte cinematográfica, outra é a presença de aspectos ficcionais do documentário, como constatam os dois exemplos acima mencionados. Trata-se de um deslocamento no regime imagético, em que imagens documentais convivem com imagens fabricadas, acompanhado por uma forte presença da encenação - conforme dito anteriormente, um apelo à ficção. $\mathrm{O}$ autor como personagem, ou a família como personagem, ou mesmo a encenação de personagens documentais compõem outro grupo de filmes classificados por Gonçalo, que têm como centro o uso da performance como ferramenta cinematográfica. O céu sobre os ombros (Sergio Borges, 2011) apresenta três personagens que encenam a própria vida diante da tela, característica também irrestrita ao universo brasileiro, como demostra o exemplo de Sacro Gra (2013), do italiano Gianfranco Rosi, com um número maior de personagens. Esses dois filmes, documentários que lançam mão da encenação do outro como forma primordial, demonstram que a discussão sobre real x ficcional pode ser tão vasta quanto nosso tempo de vida na terra, tanto é que os trabalhos, a leitura, a visão, as teorias cinematográficas e literárias nunca chegam a um acordo, justamente porque lidam com regimes não pertencentes unicamente ao fazer narrativo, mas também à própria vida humana (ISER, 2013).

Iser afronta este terreno minado e oferece um modo de enxergar este oposto tácito de uma forma menos dualista, pois defende que, para erigir uma narrativa ficcional, operamos através de uma tríade: real-fictício-imaginário. Para que haja a ficção, é preciso passar pelas etapas de seleção, combinação e autoindicação. Em poucas palavras, o real é a matéria-prima de onde retira-se temas, impressões, inspirações, sendo que os campos de referência do que será selecionado são de natureza sociocultural, bem como de natureza literária ou cinematográfica. “A seleção é uma transgressão de limites, na medida em que os elementos acolhidos pelo texto agora se desvinculam da estruturação semântica ou sistemática dos sistemas de que foram tomados" (ISER, 213, p. 35). Ainda mais importante, a seleção "retira-os desta identificação e os converte em objetos da percepção" (ISER, 213, p. 35). A operação seguinte é a de combinação, quando entram em jogo os elementos textuais - no caso do cinema, as escolhas sígnicas, estéticas, de montagem, as quais estão inevitavelmente inseridas em um universo intertextual que compreende o que foi feito e o que se faz em cinema. Finalmente, o texto (literário ou cinematográfico) apresenta-se como se, isto é, ao mesmo tempo em que assume sua ficcionalidade, apresenta-se como se fosse real:

O sinal de ficção no texto assinalado é antes de tudo reconhecido através de convenções determinadas, historicamente variadas, que o autor e o público 
compartilham e que se manifestam nos sinais correspondentes. Assim, o sinal de ficção não designa nem mais a ficção como tal, mas sim o "contrato" entre autor e leitor, cuja regulamentação comprova o texto não como discurso, mas sim como discurso encenado (ISER, 2013, p. 42).

Irmãs Jamais lança mão de aspectos (materiais e temáticos) autobiográficos do diretor Marco Bellocchio, mas é classificado como drama, ou seja, ficção. A hipótese que guia esta pesquisa é a de que o afrouxamento do contrato ou a circularidade dos pactos executada por Bellocchio neste filme dá a ver concretamente o pensamento de Iser acerca dos sustentáculos da ficcionalidade, indo além: quando o cineasta opta por escolher imagens que, dentro da ficção, têm apelo documental, e por dar ao expectador informações sobre a produção do filme, escancara os processos subjacentes ao fictício e, ao mesmo tempo, transgride um "não-gênero em formação" - se, assim, podemos chamar as escritas de si - cujas características procuramos descrever aqui. Ao chacoalhar ainda mais as supostas fronteiras que definem o que é invenção, realidade, signo, ícone, narrativa ou memória, o filme aponta seja para os ritmos de recepção a que estamos habituados, como também para o imaginário como uma espécie de terreno que une e faz conviver aquilo que costumamos chamar de ficção e documentário.

\section{Os Jamais}

No início do filme, Giorgio, um dos protagonistas, lê um trecho de As três irmãs, de Anton Tchekhov, enquanto ouvimos o badalar de um sino, e a sequência é cortada por imagens de outro filme, em preto e branco. A fala é de Andrei Serguêievitch, um dos personagens da peça tchekhoviana:

\footnotetext{
A nossa cidade tem já duzentos anos, conta cem mil habitantes, mas não há um único ser que não se assemelhe aos demais, nunca houve um único herói, no passado e nem no presente, não há nenhum sábio, um único artista sequer, não há uma só pessoa merecedora de um mínimo de atenção, capaz de despertar a inveja ou um desejo apaixonado de imitá-la... Elas se limitam apenas a comer, beber, dormir... Depois morrem... Nascem outras, que também comem, bebem, dormem [...] (TCHEKHOV, 1982, p. 63).
}

Na peça de Tchekhov, as irmãs são apresentadas como uma única personagem, apesar de darem nome à obra, "OLGA, MACHA E IRINA, irmãs de Andrei Serguêievitch”. As irmãs de Bellocchio são Letizia e Maria Luisa, mulheres que foram, nas palavras do diretor, "de alguma forma obrigadas a permanecer na proteção de um bem-estar provinciano e a desistir da 
possibilidade de escolher outra vida. [...] sinto um afeto profundo, [...] melancólico, se comparo minha vida com a delas",

O enunciado "as irmãs de Bellocchio", usado acima, refere-se às irmãs do filme realizado pelo cineasta Marco Bellocchio e também às irmãs do indivíduo Marco Bellocchio. Se outros parentes comparecem na trama assumindo papéis ficcionais, as irmãs do título encenam a própria vida. Em seu aspecto mais autobiográfico, o filme é, portanto, um acerto de contas com uma espécie de culpa, segundo as declarações do cineasta, pela vida que as irmãs (não) tiveram. Delas, somente o sobrenome é fictício: Mai, (em português, Jamais), simboliza, então, uma herança familiar, a força de um destino traçado para aquelas pessoas, que permanece nas gerações vindouras. Além das irmãs Bellocchio, os personagens principais são Giorgio Mai, interpretado por Piergiorgio Bellocchio; Sara Mai, interpretada por Donatella Finocchiaro; Elena Mai, interpretada por Elena Bellocchio; e Gianni, o grande amigo da família (no filme e na vida). As outras aparições são mais secundárias, mas ainda reúnem a atuação do irmão do diretor e de sua esposa, responsável pela montagem do filme.

O diálogo com a peça de Tchekhov é, portanto, uma chave interpretativa para Irmãs Jamais, dada já na primeira sequência com a leitura em voz alta, pelo personagem Giorgio, do trecho acima transcrito. Ademais, vem a sublinhar essa chave de leitura a montagem dialética com cenas do primeiro filme de Bellocchio, De punhos cerrados (I pugni in tasca, no original), de 1965, de onde foram recortadas as imagens em preto e branco. A conversa entre os filmes é temática, pois a família de seu primeiro filme, muito aclamado pela crítica, é disfuncional: uma família burguesa em que todos os membros ou sofrem de epilepsia, ou são frios a ponto de uns não se importarem com o assassinato dos outros. A crítica à autoridade familiar é muito mais feroz neste seu filme de estreia, e o diálogo com o mesmo acaba por sugerir a loucura da família Mai, que, no entanto, é muito mais próxima ao que quase todos nós vivemos dentro de nossas próprias famílias. Além do mais, a conversa com De punhos cerrados também é temporal e formal, um gesto de recordação para imprimir a repetição na forma: o cineasta retoma sua cidade natal, Bobbio, a casa em que cresceu, além da problemática familiar, que em Sorelle Mai é mais da ordem do existencial do que do doentio. Assim, se no primeiro filme esta paisagem serviu como cenário e temática, cumprindo uma função importante na diegese

\footnotetext{
${ }^{5}$ Traduzido do original: “...costrette in qualche modo a restare nella protezione di un benessere di provincia e, in qualche modo, a rinunciare alla possibilità di scegliere un'altra vita $[\ldots]$ ho un affetto profondo $[. .$.$] malinconico$ se confronto la mia via con la loro" Disponível em: http://trovacinema.repubblica.it/news/dettaglio/bellocchio$\underline{\text { racconta-la-sua-famiglia/400884/ }}$
} 
fílmica, em Sorelle Mai, o mesmo cenário ganha contornos autobiográficos mais fortes, pela presença dos parentes: o paratexto, desde a capa do DVD até toda a informação veiculada na grande mídia, a encenação da própria vida pelas irmãs Bellocchio e a imagem de Elena, de quem acompanhamos o crescimento, são os principais vetores para esta leitura.

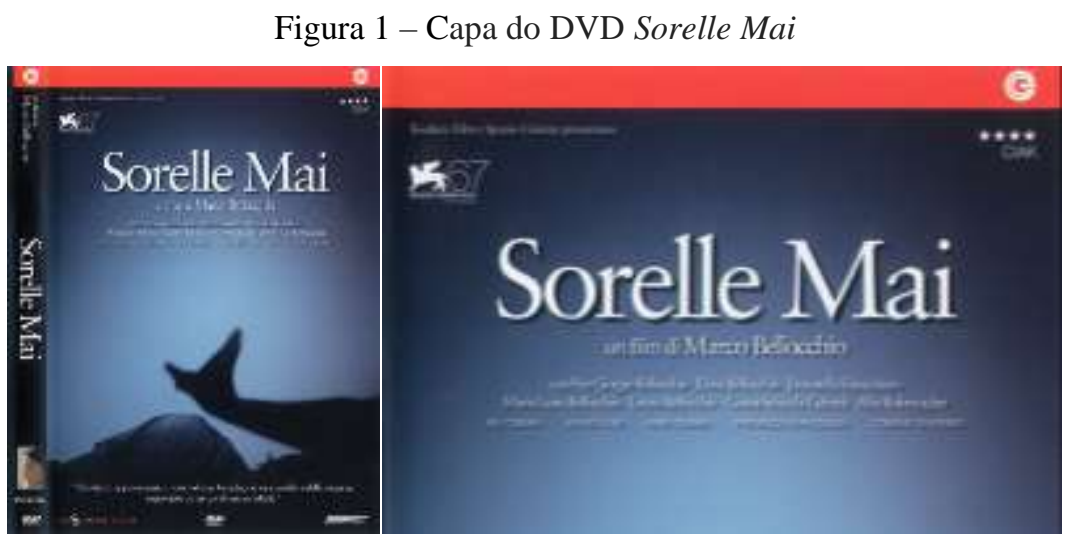

Fonte: 〈http://www.fasterage.net/vb/threads/1791-Sorelle-mai $>$.

Os protagonistas são Sara e Giorgio, dois irmãos que compartilham o desejo de consolidar a careira artística, os quais transitam por Bobbio por conta da filha de Sara, Elena, e das tias, Maria Luisa e Letizia, com quem Elena mora. Piergiorgio e Elena são filhos de Marco Bellocchio, e Donatella é a atriz contratada para comparecer a partir do terceiro episódio, para materializar a figura de Sara, personagem que já existia desde o primeiro.

O conflito inicial de Irmãs Jamais é dado pela ausência de Sara em Bobbio e nos cuidados com Elena, o que indispõe Giorgio por dois motivos: acaba por tornar-se responsabilidade sua os cuidados com a menina de 4 anos, dever que o impede de fazer o que a irmã está fazendo, isto é, procurar uma oportunidade de trabalho ou consolidar a carreira artística em Roma ou Milão. A trama desenvolve-se, então, impulsionada por pequenos conflitos que retratam as condições de Sara, Giorgio, Elena, acompanhados pela presença paradoxalmente reconfortante e incômoda das irmãs Jamais, símbolos de um estilo de vida provinciano, enraizado, comum em um lugar onde nada acontece.

Pequenos conflitos são o centro de cada um dos 6 episódios do filme, correspondentes a cada ano de atividade no Laboratorio Fare cinema. O primeiro deles é o da mãe ausente, situação que se lamenta e se resolve entre os que estão presentes em Bobbio. Sara é comparada ao tipo de mãe que uma sociedade paternal considera correto: a mãe que se sacrifica, que abdica dos próprios desejos, que faz suas escolhas colocando o filho em primeiro lugar. Sara, a mãe 
ausente do filme, só aparecerá no terceiro episódio, quando o diretor já pensava em unir as partes em um longa-metragem, no futuro. No entanto, o filme constrói a ideia de uma mãe que precisou partir para realizar seus desejos, mas que soube manter um vínculo forte com a filha.

$\mathrm{O}$ fato de terem sido filmados como curtas-metragens por aprendizes de cinema concretizou no filme um amadorismo da imagem que, por fim, tornou-se sua estética. A impressão visual do filme como um todo é composta de texturas variadas, é apresentada em muitos momentos sem refinamento de cor, o que acaba por consolidar uma palidez que fica impressa na memória do espectador. Algumas cenas apresentam estética documental pela precariedade da granulação e, em alguns momentos, porque nosso olhar as vê assim, já que sabemos dos vínculos extradiegéticos dos atores. Neste sentido, além da qualidade irregular da imagem, o extrafílmico tem papel fundamental, porque faz ver um formato diferente, mudando a chave perceptiva do espectador: além de toda a informação paratextual já mencionada, no início do filme, são apresentados os anos de realização dos episódios e o nome da escola de cinema. Cientes da origem das partes do filme, da matéria-prima e das condições de produção, o expectador não somente vê os atores para além dos personagens, mas também vê com mais nitidez os rumos tomados para que os curtas se tornassem depois um longa-metragem.

Isolados um do outro, os saltos temporais entre cada episódio apresentam toda uma carga de informação que sublinha o sentido de prisão e permanência que vai se imprimindo desde o título e o trecho de As três irmãs. Como, por exemplo, no retorno de Elena a Bobbio, depois de uma tentativa de morar com a mãe em Milão. Entre a efetivação da mudança e o retorno à casa das tias, há uma elipse temporal, um não-dito, cujo sentido se pressupõe ao vermos a menina novamente em Bobbio, sem a mãe, vivendo sua vida adolescente. Não sabemos se a mãe obteve ou não sucesso no papel de protagonista que conseguira em uma peça, pois nada é dito a respeito, nem retomado no episódio seguinte. Como se importasse somente a permanência dos laços com aquele lugar, sob as asas das irmãs Jamais. "Não-ditos" possivelmente lidos como falha de roteiro, se não soubéssemos da precariedade do planejamento e dos vazios com que a etapa da montagem deve ter tido que lidar. Mas essas "falhas" são constituintes do filme e dão a ele seu valor cinematográfico e temático.

Juntos, a trama em episódios torna-se o retrato de uma família, ou de um entendimento de família, acompanhado de um efeito de amargura e ternura ao mesmo tempo. E percebe-se que é justamente na tensão entre a amargura e a ternura que se constrói o filme, a forma escolhida de dar ao termo família um conceito próprio, distanciado da crítica atroz realizada por De punhos cerrados, atualizada por um sentimento de pesar por parte do cineasta. 
Amargura pela prisão interiorana, pelo desejo de sucesso não alcançado, por tentar fugir de uma sina e não ser capaz. Diz a força do sobrenome Jamais: não adianta tentar, ou melhor (pior), não é preciso tentar, pois aqui já temos nossa casa, nosso rio, a catequese, oportunidades de trabalho e até nossa capela no cemitério. A amargura é o fio puxado por Giorgio, o personagem que vive o fracasso, ano após ano, no amor, no dinheiro, na profissão. Os motivos do fracasso não são vistos, pois vivem nas elipses entre um episódio e outro, como em um movimento de memória, fragmentado, de descontinuidade. O que vemos é sua presença amargurada em Bobbio, em busca da irmã, do dinheiro das tias, em fuga de credores, ou porque não lhe resta outro lugar. Por outro lado, ternura pelos laços familiares fortes que se mostram existentes a despeito da distância. Os cuidados de Giorgio para com a sobrinha, a amizade cúmplice entre os irmãos, o amor de Elena pela mãe e pelo tio. E até mesmo o cenário, que para os irmãos Sara e Giorgio é sinônimo de prisão e fracasso, preenche-se de ternura na perspectiva de Elena. É a personagem Elena, cujo crescimento acompanhamos através dos anos, quem puxa o fio da ternura. As cenas externas, o rio Trebbia, as festas de rua e, mais importante, a materialização da infância de forma documental, que acompanha quase dez anos da vida de Elena Bellocchio, lembram que, no cinema, nada é mais forte do que o envelhecimento real, sem truques de maquiagem ou de montagem, para nos lembrar do caráter incriminador da fotografia.

Marco Bellocchio parece ter optado por unir uma necessidade prática a uma operação afetiva, pois, ao mesmo tempo em que usa, para ensinar seus alunos do laboratório, a matériaprima imagética que tem por perto, ou seja, seus próprios filhos e irmãs, faz um registro de sua família e, de certa forma, desloca a fricção mais comum entre ficção e realidade, já tão explorada nos documentários subjetivos da época recente, a uma forma nova, que gera um problema de pacto de leitura ao revés: se o filme desnuda sua ficcionalidade ao ser classificado como drama, ao mesmo tempo, por ser também identificado como escrita de si, propõe reflexões outras, principalmente sobre o tempo e a produção de imagens. Adotando uma escrita pessoal indireta, através da ficção, através da própria família, o mais perto que chegamos da figura de Marco Bellocchio será através de sua reflexão sobre o cinema.

\section{Imagens pálidas}

Em Espaços da recordação, Aleida Assmann (2011) empreende um estudo impressionante sobre as formas de concepção, exercício, função, armazenamento da memória desde os egípcios. Explica terminologias como as de memória experiencial x memória cultural, 
memória funcional e cumulativa, e descreve formas como a memória foi concebida no passado, como por meio dos conceitos de ars (arte) e vis (potência): a memória como arte equivale à capacidade e à importância do armazenamento, enquanto a memória tida como potência lança o paradigma da recordação formadora de identidade. A autora atesta que a mnemotécnica, ou a arte de acumular conteúdo na memória, hoje vai de mal a pior: se temos hard disks ao nosso dispor, já não há tanta serventia em dispensar energia decorando conhecimento que está a um clique de distância, visto que "as máquinas conseguem armazenar o que o homem também consegue quando utiliza a mnemotécnica correspondente, dentro de certos limites" (ASSMANN, 2011, p. 34). Mas os seres humanos também conseguem recordar, coisa que as máquinas até hoje não estão em condições de fazer.

Gostaria, por isso, de opor ao procedimento de armazenamento o processo de
recordação [...] A recordação procede basicamente de forma reconstrutiva: sempre
começa do presente e avança inevitavelmente para um deslocamento, uma distorção,
uma revaloração e uma renovação do que foi lembrado até o momento da sua
recuperaçãa. Assim, nesse intervalo de latência, a lembrança não está guardada em
um repositório seguro, e sim sujeita a um processo de transformação. A palavra
"potência" indica, nesse caso, que a memória não deve ser compreendida como um
recipiente protetor, mas como uma força imanente, como uma energia com leis
próprias [...] O ato do armazenamento acontece contra o tempo e o esquecimento,
cujos efeitos são superados com a ajuda de certas técnicas. O ato da recordação, por
sua vez, acontece dentro do tempo, que participa ativamente do processo
(ASSMANN, 2011, p. 34).

Esse tipo de trabalho de rememoração foi encontrando, paradoxalmente, meios e formas de armazenamento diversos, conforme as contingências epocais. Mas, se antes acreditava-se na escrita como a mídia mais transparente, "emanação do espírito", e que a literatura era a forma ideal de encontro com um tempo perdido, também, desde o século XIX, historiadores como Pierre Nora ou Aby Warburg descobriram as imagens como fontes históricas - às quais, no entanto, não se aplica mais a transparência, mas sim uma "ambivalência irredutível", dado que as imagens e os símbolos são vistos como "manifestação de um afeto ou do inconsciente" (ASMANN, 2011, p. 237). As imagens, em sua ambivalência ou intransparência, são naturalmente tanto armazenadores como partícipes de processos de recordação. Neste estudo arqueológico, a autora oferece-nos, portanto, uma possibilidade de compreensão maior e atual sobre memória como potência e sua relação com as mídias, sejam elas textos, imagens ou discursos (cinema, literatura, história, psicologia etc.).

Mas as imagens do filme Irmãs Jamais não são imagens de arquivo, recuperadas para um exercício de memória; ao contrário, são imagens produzidas para o presente de então, com um objetivo prático: ensinar a fazer cinema. No entanto, não se pode deixar de apontar um possível 
desejo de armazenamento de imagens do passado pelo cineasta. Temos, assim, ao mesmo tempo, imagens que se dão a ver para um destino prático, o de aprender a lidar com elas, e também se dão a perceber de forma completamente outra, ressignificada, porque são montadas em um filme que as costura, são acompanhadas da assinatura de um autor (no sentido foucaultiano) e ganham o estatuto de recordação, de filme de família.

[A fotografia] Esse auxilio à recordação pode ter contornos de granulação fina e foco excelente, mas não fala. Eis porque a memória das fotografias, excelente e inesgotável, assume vida própria como recordação fantasmagórica, tão logo se suspenda o texto narrativo e comunicativo que as emoldura (ASSMANN, 2011, p. 238).

A recepção que se tem das imagens feitas por alunos de um laboratório de cinematografia e das mesmas imagens vistas hoje por nós, sob a égide das discussões acerca das escritas de si no cinema, aponta para um modo de leitura específico que, por conta de informações de apresentação, intertextuais e aspectos da imagem, prepara o espectador a ser capaz de retirar o texto narrativo das imagens apresentadas e ver imagens de recordação para além de seu papel na composição da diegese. Trata-se de um aparente paradoxo decomposto em dois regimes de visualidade que o filme consegue suster para imaginar, no sentido iseriano, uma ideia de família.

A potência de recordação, diferente daquela que a História narrativiza, é um dos desejos que fazem mover muitos dos trabalhos subjetivos do cinema contemporâneo. O que parece inaudito é que este tipo de memória, parceira do esquecimento porque é dele dependente, tem encontrado um desejo de armazenamento, ousaríamos dizer, com o intuito de transformar em memória cultural uma forma de exercício da subjetividade, bem como de pensamento sobre a autoria, o ego, sobre as mídias narrativas, o real e o virtual, sobre a palavra e a imagem, ou seja, sobre tudo o que se faz urgente contemporaneamente.

\section{Aberturas}

Considerada a filmografia de Marco Belocchio, Irmãs Jamais é um filme delicado. Habituado a lidar com abordagens contundentes de temas universais, como a morte em Faibeisogni (2016) e Bella addormentata (2012), o extremismo político em Vincere (2009) e Buongiorno notte (2003), a autoridade e o fundamentalis moreligioso em Sangue del mio sangue (2015), dentre outros, as imagens e sua qualidade sempre foram impecavelmente escolhidas, marcantes, quase violentas. As imagens de Irmãs Jamais são pálidas porque 
destoam deste conjunto e imprimem no espectador um sentimento opaco, difícil de nomear, talvez porque se encontram justamente entre a ternura e a amargura, e a língua portuguesa não tenha uma palavra para ele. Em oposição às imagines agentes, marcantes como as querem a publicidade, bem descritas por Assmann (2011, p. 238-241), o conceito de imagem pálida parece encaixar-se nesta falta de significante.

A primeira versão do filme é um média-metragem que pode ser acessado nos extras do DVD. A maior diferença entre uma e outra versão, além da ausência de alguns episódios, é a forma como iniciam: a versão abandonada apresenta uma sequência de fotografias de época que instauram uma ambiência que o longa-metragem procura evitar. Não vemos um filme sobre o passado de uma família, mas as imagens de(ssa) família sobrevivem de outra forma, pois fogem do gênero "filme de época" e encontram a singularidade no todo: um filme ficcional sobre o tema da família que oferece uma reflexão que supera a temática (e tudo que dela se desdobra) e alcança um pensamento sobre o cinema - e tudo o que disso se desdobra.

A cena final de Irmãs Jamais é difícil de explicar ou compreender. Giorgio faz o papel de diretor da cena filmada tendo Gianni como ator, que, por sua vez, interpreta o homem de fraque (da canção L'uomo in frac), ou o momento de sua morte/suicídio. Gianni caminha para dentro do rio, até que vemos sobrar na superfície somente seu chapéu, mas ele não retorna das águas; assistimos a uma morte em cena. Imersos no ritmo do filme, a leitura pode sugerir um acontecimento real, testemunhado pelas câmeras amadoras e pelas câmeras que filmam a cena, em mise em abyme. Gianni morre no filme, ou no filme do filme, ou morre no filme dos alunos? Ainda que pareça uma leitura ingênua, é preciso confessar que ela é possível. A hipótese é que Marco Bellocchio, com seu vício pela abertura, não tenha resistido a nos deixar uma imagem menos pálida, impressa na memória, alocada em um lugar entre as camadas do filme, impalpável como é o imaginário.

\section{Referências}

ASSMANN, Aleida. Espaços da recordação: formas e transformações da memória cultural. Campinas, SP: Editora da Unicamp, 2011.

GONÇALO, Pablo. The subjective turn in Brazilian documentaries. Paper apresentado na Conferência LASA, 2012. Disponível em: <https://www.academia.edu/3350002/The subjective turn_in_Brazilian_Documentaries $>$. Acesso em: 18 de março de 2017. 
IRMÃS Jamais. Direção: Marco Bellocchio. Itália, Provincia di Piacenza, Comune di Bobbio: Teodora Film e Spazio Cinema, 2010. 1 DVD (104 min.). son., color., legendado em italiano.

ISER, Wolfgang. Atos de fingir. In: O fictício e o imaginário: perspectivas de uma antropologia literária. Rio de Janeiro: EdUERJ, 2013.

LEJEUNE, Philippe. O pacto autobiográfico: de Rousseau à internet. Belo Horizonte:

Editora da UFMG, 2008.

MARTONI, Alex; ULM, Hernán. O gesto de ouvir música em Vilém Flusser: tecnologias de áudio e rituais da percepção. Revista Eco-Pós (Online), v. 19, p. 170-189, 2016.

SALVATORE, Rosamaria. Vedere con l'inconscio: Sorelle Mai tra autofinzione e autoritratto. In: Lostato delle cose: cinema e altre derive. Torino: Edizioni Kaplan, 2012.

SORELLE, Mai. Capa do DVD. Direção: Marco Bellocchio. Itália, Provincia di Piacenza, Comune di Bobbio: Teodora Film e Spazio Cinema, 2010. 1 DVD (104 min.). son., color., legendado em italiano. Disponível em: : <http://www.fasterage.net/vb/threads/1791-Sorellemai >. Acesso em: 14 de março de 2017.

SCAMPARINI, Julia S. O sujeito na mídia: escritas de si literárias e fílmicas. Revista Ipotesi (Juiz de Fora. On-line), v. 19, p. 258-269, 2015.

Presença do autor: autoficções de Ricardo Lísias e de Lucia Murat. Revista

Itinerários (UNESP. Araraquara), v. 1, p. 277-286, 2013.

TCHEKHOV, Anton. As Três Irmãs/ Contos. São Paulo: Abril, 1982.

Recebido em 04/06/2019

Aceito para publicação em 24/10/2019 